2 Kennie DC. Health maintenance of the elderly. Clinics in Geriatric Medicine 1986;2:53.

3 Vetter NJ, Jones DA, Victor CR. Effect of health visitors working with elderly patients in general practice: a randomised working with elderly patients in general pract

4 Tulloch AJ, Moore V. A randomised control trial of geriatric screening and surveillance in general practice. $f(R$ Coll $G e n$ Pract 1979;29:733.

5 Luker KA. Health visiting and the elderly. Nursing Times 1981 Dec 16: 137.

6 Hendriksen C, Lund E, Strømgard E. Consequences of assessment and intervention among elderly people: a three year randomised control trial. $\mathrm{BrMed}$ f 1984;289:1522.

7 Williams EI. Characteristics of patients aged over 75 not seen during one year in general practice. $\mathrm{Br}$ Med f 1984;288:119.

SIR,-Dr Simon Barley's article illustrates several common misconceptions about health care of the elderly.

Firstly, he hints that it is unthinkable that health visitors should stop doing things that they already undertake. In the same edition of the $B M F$, however, Ms Emily Grundy (p 626) shows that health visitors have already altered their practice. Between 1976 and 1984 they reduced their visits to the over $75 \mathrm{~s}$ by $15 \%$, thus opting to neglect the group with the most severe health problems. In the light of this shameful fact it is essential that they should reconsider their current practice and how they will allocate their time in the future.

Secondly, the concept of employing 1900 additional staff seems unrealistic to Dr Barley. On the other hand, Mrs Cumberlege's report advocated that practice nurses should be abolished, pointing out that continuing the current arrangements could necessitate the employment of an additional 20000 nurses, mainly at the expense of central funds. General practitioners have argued for the retention of this facility, and the government seems willing to continue to foot the bill. So money and manpower can be made available for some actions but not for others.

The care of the elderly, both in the community and in hospital, is expensive in time, money, and manpower. If we are to treat elderly people as they deserve and need we must face the financial consequences. There will be serious humanitarian consequences if we fail to fulfil our duties. The degree of civilisation of a society (or profession) may be judged by its attitudes to the care of the elderly.

S G P WEBSTER

Department of Geriatric Medicine,

Addenbrooke's Hospital

Cambridge CB2 $2 \mathrm{QQ}$

\section{Orchidectomy versus oestrogen for prostatic} cancer: cardiovascular effects

SIR,-With regard to Dr T W Meade's comments (11 October 1986, p 953), the last 20 patients in the randomised study were evaluated with regard to activators and inhibitors of blood coagulation and fibrinolysis. ${ }^{1}$ Before treatment the patients with prostatic carcinoma already had increased concentrations of fibrinogen and factor VIIIC compared with healthy controls of the same age. During oestrogen treatment factor VII concentration rose significantly $(p<0.001)$ and the antithrombin III concentration decreased significantly $(p<0.001)$. With regard to fibrinolysis, plasminogen concentration increased and that of urokinase inhibitor fell $(p<0.001)$ after treatment with oestrogen was started.

Thus patients with prostatic cancer receiving oestrogen treatment have increased concentrations of factor VII, factor VIIIC, and fibrinogen. All these changes are identical with the findings that predicted death in patients with ischaemic heart disease in the prospective Northwick Park heart study. ${ }^{2}$ In addition, the patients' concentrations of antithrombin III decrease and the fibrinolytic capacity seems to increase during oestrogen treatment. Fibrinolysis was also activated in many of the patients who received oestrogen, as judged by increased concentrations of a fibrinogen degradation end product, the so called $\mathrm{D}$ dimer, during treatment.

P HENRIKSSON

M BLOMBÄCK

G BRATT

O EDHAG

A ERIKSSON

Department of Internal Medicine,

Huddinge Hospital

S-141 86 Huddinge,

Sweden

Henriksson P, Blombäck M, Bratt G, Edhag O, Eriksson A Activators and inhibitors of coagulation and fibrinolysis in patients with prostatic cancer treated with oestrogen or orchidectomy. Thromb Res 1986;44:783-93.

Meade TW, Chakrabarti R, Haines AP, North WRS, Stirling Y, Thompson SG. Haemostatic function and cardiovascular death: early results of a prospective study. Lancet 1980; $1050-4$

\section{Barrett's oesophagus}

SIR,-Dr R C Heading (21 February, p 461) cites many references that fail to explain the true nature of this condition. He and other authors regard the anomaly as being acquired and refer to such things as short oesophagus, gastric lined lower oesophagus, Barrett metaplasia, and heterotopic gastric cells.

The title Barrett's oesophagus is a misnomer, and $\mathrm{Mr}$ Barrett laid no claim to the eponym but described a chronic ulcer in the lower gullet, which is lined with columnar epithelium. ${ }^{\prime}$ A clear distinction between this and superficial ulceration associated with reflux oesophagitis has now been established.

Before accepting a meaningless eponym we should find a name that relates to development and anatomy and thus explains the true nature of the anomaly and its origin. The development of the oesophagus is complex but has two remarkable features ${ }^{2}$ : firstly, rapid elongation from a length of $1 \mathrm{~mm}$ in the $5 \mathrm{~mm}$ ( 35 day) embryo to reach its full length at birth, and, secondly, the unique pattern of epithelial formation. Differentiation of the gut epithelium occurs in a regular pattern, which starts at the $15 \mathrm{~mm}$ stage and is well advanced in the $17 \mathrm{~mm}$ embryo. Vacuolation of the primitive endodermal tube starts around the 5th week (14 mm embryo), and the columnar lining cells are gradually replaced by squamous cells to become mature squamous cell epithelium. This is a gradual change, however, which progresses from the cranial to the caudal end of the primitive gullet, so that at any given time a squamous lined proximal segment of variable length merges with a distal part lined by cells in various stages of metaplasia.

Usually, elongation and metaplasia are complete at birth, but if they are not a lower segment of variable length will retain a columnar lining into advanced pregnancy or until full term, and in some cases into adult life. If oesophagogastric function is competent there may be no symptoms, and as there is no need for endoscopy to be performed the condition may never be diagnosed. But incompetence often occurs in patients with this anomaly, and reflux oesophagitis occurs either in the very young or in later life, when the incompetence may be aggravated by hiatal herniation. Ulceration, with fibrosis and stricture formation, may occur in the squamous epithelium near the columnar lined segment and, depending on the length of this, may be near the cardia or as a high stricture at around 28 or $30 \mathrm{~cm}$
Large numbers of histological reports will continue to be written and the confusion over the terms used will persist unless the complex developmental processes are studied. Acquired changes do occur as a result of gastro-oesophageal reflux over the multipotential cells of the columnar lining, which is in itself a congenital abnormality.

It has been suggested that there is no sound support for the view that this condition is acquired and that many terms used to describe it should be discarded. Congenital columnar lined lower oesophagus would be a suitable name.

JOHN HUTCHISON

Bearsden,

Glasgow G61 1BZ

1 Barrett NR. Chronic peptic ulcer of the oesophagus and oesophagitis. Br f Surg 1950;38:175-82.

2 Hutchison J, Thomson JD. Congenital archenteric cysts. $\mathrm{Br} \mathcal{f}$ Surg 1953;41:15-20.

AUTHOR'S REPLY-Is Barrett's oesophagus congenital or acquired? The debate has been going on for some years, with most of the reports of the 1950 s and 1960s supporting a congenital origin for various reasons, including the embryology described by $\mathrm{Mr}$ Hutchison. Since then, however, the view that Barrett's oesophagus is an acquired lesion has gained favour, with the recognition that the columnar epithelium has features that indicate that it is metaplastic (that is, it is an epithelium that has replaced a different, earlier type) and that operative treatment that suppresses gastrooesophageal reflux may allow reversion to a normal squamous oesophageal lining. One weakness of this theory is that there is no good explanation of why some patients with gastro-oesophageal reflux develop Barrett's oesophagus while others do not. There is perhaps an analogy in the gastric mucosa: it is not clear why some patients with gastritis develop extensive intestinal metaplasia, which does not occur in others.

The proposal that Barrett's oesophagus should be renamed congenital columnar lined lower oesophagus is logical if we are confident that the condition is indeed congenital. I believe, however, that most gastroenterologists do not share $\mathrm{Mr}$ Hutchinson's conviction and that the balance of evidence favours the view that Barrett's oesophagus is an acquired lesion.

R C HEAding

University of Edinburgh

Edinburgh EH3 9YW

\section{AIDS and intravenous drug use}

SIR,-Dr J R Robertson and Carol Skidmore (28 February, $p$ 571) produce a table relating the year of starting heroin addiction to the presence of antibody to the human immunodeficiency virus (HIV). They interpret the high prevalence among those who became addicted in $1982-3$ as being due to some other factor or factors operating in these years and suggest that "a minor epidemic of heroin use resulted in extreme and damaging behaviour, giving rise to ideal conditions for transmission of virus."

We would interpret their data differently. In our study relating sexual lifestyle to HIV antibody state in homosexual men we found that those who had practised a gay lifestyle for five years or less had a significantly lower prevalence of HIV antibody than those who had practised for more than five years. ${ }^{1}$ Our figures showed that of the 98 who were HIV seropositive, 91 (93\%) had been homosexually active for more than five years, compared with 153 of $206(74 \%)$ of those who were sero- 
negative $(p<0.001)$. Interpreted in a similar way, Skidmore show that 63 of $69(91 \%)$ patients who were seropositive had been addicted for more than three years, compared with 34 of $54(63 \%)$ who were seronegative $(\mathbf{p}<0.001)$.

In our paper we also showed that homosexual activity for more than five years was the strongest predictor of seropositivity, and we postulated that an additional factor may be necessary for HIV infection to become established. Such a cofactor may be present in those who have practised a high risk lifestyle for several years, which would account for the apparent failure of HIV infection to spread appreciably outside these groups. Perhaps the most likely candidate for this cofactor is another infection.

B A Evans

K D MACRAE

\section{West London Hospital,}

London W6 7DQ

1 Evans BA, Dawson SG, McLean KA, et al. Sexual lifestyle and clinical findings related to HTLV/LAV status in homosexual men. Genitourinary Medicine 1986;62:386-91. the data presented by Dr Robertson and Ms

SIR,-Dr M W McKendrick and colleagues make an astonishing statement in their letter (14 March, p 704) when they say "topical idoxuridine is thought to be effective, but we would dispute that this has ever been confirmed adequately." Years ago, my colleagues and I carried out a very elaborate double blind controlled trial. ${ }^{\text {We }}$ showed conclusively that $40 \%$ idoxuridine in dimethyl sulphoxide applied continuously to the affected segment in zoster was highly effective $(\mathrm{p}<0.0003)$. The statistics were performed by Sir Richard Doll's team and our findings have never before been disproved. Dr McKendrick and coauthors are also mistaken in their belief that $40 \%$ idoxuridine in dimethyl sulphoxide applied continuously on lint cannot be used to treat outpatients. We have treated hundreds of patients thus with very satisfactory results $(35 \%$ idoxur idine will do just as well).

I am also surprised that Dr McKendrick and colleagues published the findings of their trial of high dose oral acyclovir without any follow up. The only thing that really matters in shingles is postherpetic neuralgia. They did not refer in their paper to the Oxford double blind controlled trial of high dose intravenous acyclovir. ${ }^{2}$ We had expected that acyclovir might be only marginally effective against varicella zoster from in vitro results such as those published by Elion. ${ }^{3}$ Varicella zoster requires $30-50$ times the concentration of acyclovir to achieve inhibition similar to that found with most strains of herpes simplex virus. Though there was probably a quantitative difference between the placebo group and the patients who received 10 mg acyclovir/kg intravenously at long term follow up, some patients in both groups suffered from postherpetic neuralgia.

We know from in vitro experiments that vidarabine is several times more effective against many strains of varicella zoster than acyclovir. We treat complicated zoster (zoster of the trigeminal nerve and its branches, zoster of S2 and below, people with motor zoster, and the immunosuppressed) with vidarabine, provided that the patients are not aged over 65 . (In older people there may be unpleasant extrapyramidal symptoms, and in such patients we always use acyclovir.) Straightforward, uncomplicated segmental zoster we treat on an outpatient basis with topical $35 \%$ idoxuridine applied on lint for four days. I do not believe that giving large doses of acyclovir by mouth is justified until it has been proved that this method of administration is as good as or better than intravenous administration of acyclovir. Until we have the results of at least six months of follow up we will not know whether the expensive oral treatment advocated by Dr McKendrick and coworkers can be justified.

We still need a really good drug to treat varicella zoster. Bromvinyldeoxyuridine is one such drug, but alas it is not commercially available.

\section{B E JUEL-JENSEN}

Nuffield Department of Clinical Medicine,

ohn Radcliffe Hospital,

Oxford OX3 9DU

1 Juel-Jensen BE, MacCallum FO, Mackenzie AMR, Pike MC. Treatment of zoster with idoxuridine in dimethyl sulphoxide.
Results of two double blind controlled trials. $\mathrm{Br} \mathrm{Med} \mathrm{J}$ Results of two

2 Juel-Jensen BE, Khan JA, Pasvol G. High dose intravenous acyclovir in the treatment of zoster: a double blind placebo

3 Elion GB. In: Shiota H, Cheng Y, Prusoff W, eds. Herpes virus, clinical, pharmacological, and basic aspects. Excerpta Medica. Amsterdam: Excerpta Medica, 1982:129-54.

\section{When a woman asks for a caesarean} section

in general practice is that asthma is undertreated in childhood. This is unfortunately due to a reluctance on the part of many doctors to use inhaled or oral steroids, which is encouraged by statements like Dr Valman's that there must be good indications for their use. While I agree that this is true, I think that these drugs cause far fewer side effects than the xanthine group of drugs, which are recommended by Dr Valman for use before inhaled topical steroids.

Secondly, Dr Valman states twice that only children above the age of 4 can use dried powder inhalers. Bernstein and Sneh showed that a group of 40 children under $31 / 2$ years of age could use the Intal Spinhaler. ${ }^{+}$Of 10 of these children who were receiving oral steroids before the trial, nine were weaned off the steroid on to Intal by the Spinhaler. My own experience and that of many general practitioners shows that it is possible to teach a child, sometimes as young as $21 / 2$, to use a dry powder device or a nebuhaler.

The side effects of treatment with inhalers are far fewer than those of oral treatment, and I would suggest that general practitioners, in particular, should try to teach children to use these devices.

MARK L Levy

SIR,-I fear that Drs J G Thornton and R J Lilford (14 March, p 703) have read neither my leading article nor the paper on which it commented with sufficient care. Johnson et al advocated agreeing to perform a caesarean section, at the woman's request, on dubious medical indications, ' whereas held that the obstetrician should advise caesarean section only on clear medical indications, taking broad view of maternal and fetal mortality and morbidity risks. Thus I can hardly be suspected of promoting women's choice as I adopted the more conservative stance.

Furthermore, I find it very strange that Drs Thornton and Lilford should have dragged in the fact that I was a "defence" witness in the Savage inquiry. My views on women's choice were neither solicited nor expressed in that inquiry, and Drs Thornton and Lilford have had no other opportunity of which I am aware to ascertain my views.

Lastly, the Los Angeles trial of the delivery of the term frank breech should not be dismissed as "much too small" as it did show a much greater maternal morbidity with caesarean section than with vaginal delivery, and as this was a prospective randomised control study its conclusions on the fetal outcome of vaginal breech delivery are valuable as most studies have been smal retrospective case analyses subject to gross selection bias.

MaRion H HaLl

Department of Obstetrics and Gynaecology,

University of Aberdeen

aberdeen AB9 2ZD

I Johnson SR, Elkins TE, Strong C, Phelan JP. Obstetric decision making: responses to patients who request caesarean delivery. Obstet Gynecol 1986;67:847-50.

Collea JV, Chein C, Quilligan EJ. The randomised management of term frank breech presentation: a study of 208 cases. Am Obstet Gynecol 1980;137:235-42.

\section{Bronchial asthma}

SIR,-I would like to question two points in Dr H B Valman's otherwise excellent article on childhood asthma (21 March, p 753).

Firstly, inhaled topical steroids have been in use for the past 15 years without any reports of significant side effects. ${ }^{1-3}$ One of the main problems
Kenton,

Middlesex HA3 8JZ

1 Godfrey S, Konig P. Treatment of childhood asthma for thirteen months and longer with beclomethasone dipropionate aerosol Arch Dis Child 1974;49:591. 1983:201-5.

3 Silverman M Asthma in childhood London: Current Medical Literature, 1985:50-1.

4 Geller-Bernstein C, Sneh N. The management of bronchial asthma in children under the age of three and a half years using Intal (sodium cromoglycate) administered by Spinhaler. Clin Allengy 1980;10:503-8.

\section{Do adhesions cause pain?}

SIR,-Mr John Alexander-Williams (14 March, p 659 ), discussing the possibility that adhesions resulting from abdominal surgery might cause pain, says: "The blame also rests partly with the neurotic patients themselves, who are desperate for an explanation for their symptoms that will protect them from the feared label of "neurotic.,"

As one who deals with many letters sent to newspaper and magazine problem pages by distraught patients who have been trying every avenue open to them to find relief for their very real symptoms of distress, I find this sentence very sad. It makes clear to me why so many patients have difficulty in obtaining help with their problems. The fact that symptoms are functional rather than organic does not make them any the less distressing for the patient experiencing them. If doctors themselves regard only symptoms of organic origin as "interesting" and "real" and dismiss patients who have psychogenic pain as "neurotic" is it any wonder that patients themselves seek so desperately for physical explanations for their disease and fear the dismissive label "neurotic"?

Perhaps if more doctors were more willing to regard their patients as whole people who have to function as best they can rather than as collections of organs, which may or may not operate smoothly, there would be fewer surgeons digging into abdomens looking for adhesions as sources of pain. If patients were allowed to admit that their pain might be psychogenic and were not made to feel guilty for doing so life would be pleasanter not only

Claire Rayner

Middlesex HA1 3BU
2 Clark TJH. Steroids in asthma. New Zealand: Abis Press, for the patients but also for the doctors. 